\title{
Low-virulence phylogenetic background of CTX-M-producing Escherichia coli isolated from extraintestinal infections
}

\author{
Andyara L. Paiva ${ }^{1}$, Nilton Lincopan ${ }^{1,2}$, Ketrin C. Silva ${ }^{1}$, Patrícia R. Neves ${ }^{1}$, Andrea M. Moreno ${ }^{3}$, John A. \\ McCulloch $^{2,4}$, Claudete S. Astolfi-Ferreira ${ }^{5}$, Antonio J. P. Ferreira ${ }^{5}$ \\ ${ }^{1}$ Department of Microbiology, Institute of Biomedical Sciences, Universidade de São Paulo, São Paulo, Brazil \\ ${ }^{2}$ Department of Clinical Analysis, School of Pharmacy, Universidade de São Paulo, São Paulo, Brazil \\ ${ }^{3}$ Department of Preventive Medicine and Animal Health, College of Veterinary Medicine, Universidade de São \\ Paulo, São Paulo, Brazil \\ ${ }^{4}$ Faculty of Biotechnology, Institute of Biological Sciences, Universidade Federal do Pará, Belém-PA, Brazil \\ ${ }^{5}$ Department of Pathology, College of Veterinary Medicine, Universidade de São Paulo, São Paulo, Brazil
}

Key words: ExPEC; urinary tract infection; ESBL; CTX-M-1; CTX-M-2; CTX-M-15; ST648; Latin America

J Infect Dev Ctries 2013; 7(10):756-760. doi:10.3855/jidc.3781

(Received 10 May 2013 - Accepted 29 May 2013)

Copyright (C) 2013 Paiva et al. This is an open-access article distributed under the Creative Commons Attribution License, which permits unrestricted use, distribution, and reproduction in any medium, provided the original work is properly cited.

\section{Background}

Escherichia coli can play either a commensal or parasitic relationship with humans, with the latter leading to intestinal or extra-intestinal (EI) infections [1]. Whereas commensal E. coli strains represent predominantly (low-virulence) phylogenetic groups A and B1, strains causing EI infections (which are known as ExPEC - Extraintestinal Pathogenic E. coli) have been shown to correlate to the high-virulence phylogroups B2 and D [1,2]. However, E. coli strains exhibiting low-virulence backgrounds, such as the commensal strains, have been isolated under pathogenic conditions $[1,3]$, indicating that pathogenic commensals can cause EI infections when the bacterium gains access to a normally sterile body site, mainly in patients with susceptibility linked to underlying disease $[1,3]$.

In hospital settings, the treatment of E. coli infections has been hindered by the emergence of antibiotic-resistant strains, with extended-spectrum $\beta$ lactamase (ESBL) production being of particular concern, because third-generation cephalosporins are the drugs of choice for the treatment of ExPEC [4].

In Brazil, there is a paucity of studies on phylogenetic analysis of commensal and pathogenic ESBL-producing E. coli. The aim of this study, therefore, was to characterize the extended-spectrum $\beta$-lactamase (ESBL) production, phylogenetic backgrounds, and the clonal relationship among E. coli strains isolated from EI infections in inpatients and outpatients admitted in a university hospital, in São Paulo, Southeastern Brazil.

\section{The Study}

From January 2005 to July 2007, a total of $34 E$. coli strains exhibiting an ESBL phenotype were isolated from clinical samples obtained from 28 patients with EI in a single secondary care teaching hospital in São Paulo, Brazil. Antimicrobial susceptibility profiles were determined by Kirby-Bauer disk diffusion method [5], and ESBL production was investigated by using a double-disc synergy test and Etest ESBL strips (bioMeriéux, Marcy-l'Etoile, France). DNA amplification by PCR was used to search for $b l a_{\mathrm{CTX}_{\mathrm{M}}^{-}}, b l a_{\mathrm{TEM}^{-}}, b l a_{\mathrm{SHV}^{-}}$, $b l a_{\mathrm{GES}^{-}}$and $b l a_{\mathrm{PER}}$-type ESBL genes [6], whereas phylogenetic typing (A, B1, B2 and D) was performed by means of a multiplex PCR reaction with phylogenetic markers, chuA, yjaA, and TspE4.C2 [2]. The genetic relatedness of the isolates was determined by PFGE of $X b a \mathrm{I}$-digested genomic DNA using the protocol proposed by the National Molecular Subtyping Network (http://www.cdc.gov/pulsenet/protocols/ecoli_salmone 1la_shigella_protocols.pdf), and multilocus sequence typing (MLST) analysis was performed to characterize the genotype of CTX-M-15-producing E. coli (http://mlst.ucc.ie/mlst/dbs/Ecoli). PFGE patterns were 
Figure 1. Dendrographic analysis of PFGE ( $X b a \mathrm{I}$-digested DNA) data for ESBL-producing E. coli isolates from extra-intestinal infections. Abbreviations: ASP, antibacterial susceptibility profile (black and white squares represent resistant and susceptible isolates, respectively); AMP, ampicillin; KF, cephalothin; CRO, ceftriaxone; CTX, cefotaxime; CAZ, ceftazidime; FEP, cefepime; IMP, imipenem; GEN, gentamicin; AK, amikacin; CIP, ciprofloxacin; SXT, sulfamethoxazole/trimethoprim. Units: PICU, Pediatric Intensive Care Unit; ICU, Intensive Care Unit; EM, Emergency room; SIU; Semi-Intensive Care Unit; CC, Surgical Clinic; AMB, Ambulatory Care; NICU, Neonatal Intensive Care Unit. Gray boxes identify isolates recovered from outpatients. Strains obtained from a same patient were identified by using superscript lowercase letters " $a$ " to " $e$ ".
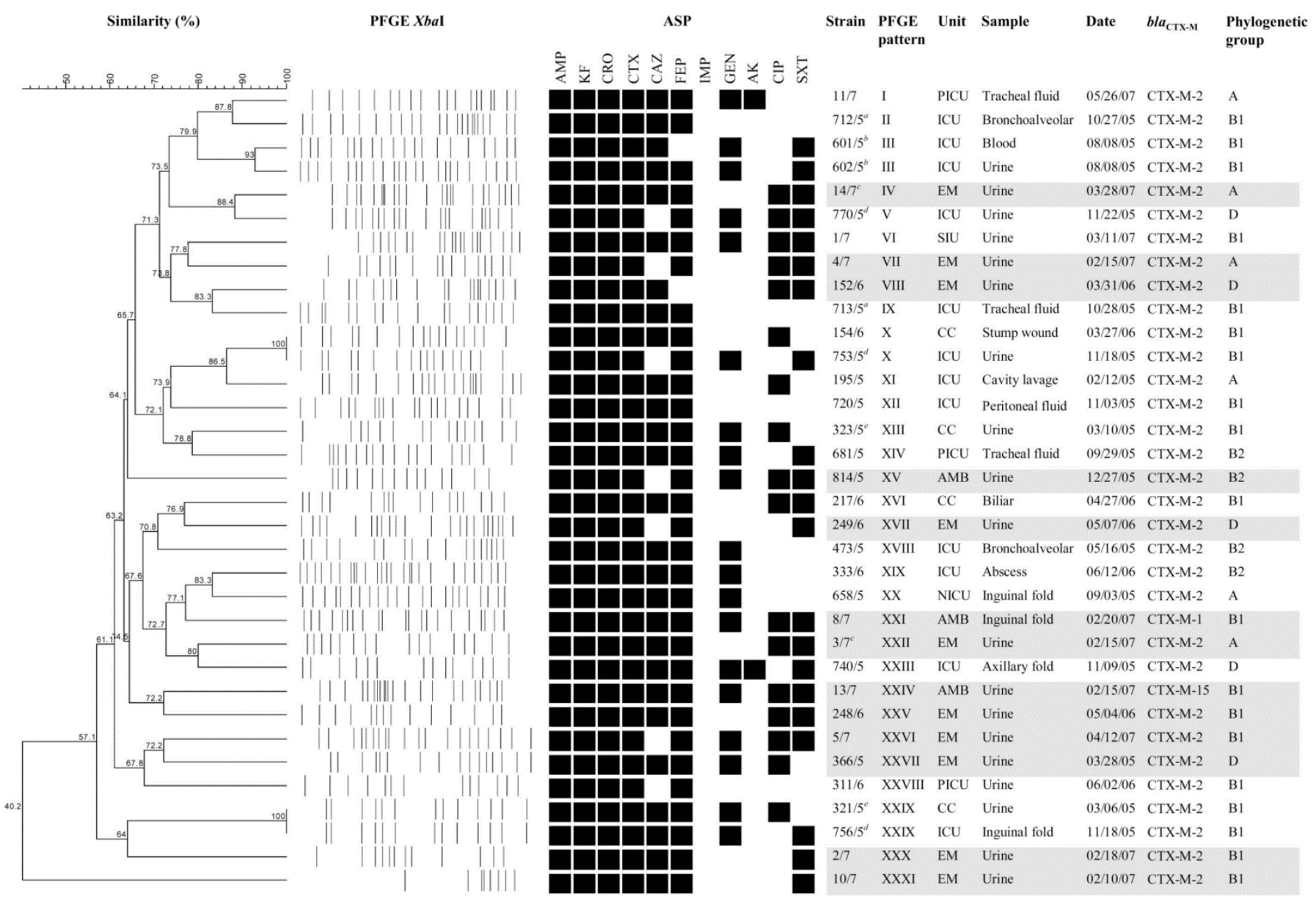

analyzed using the Dice similarity coefficient and the unweighted-pair group method using average linkages cluster method (BioNumerics software, Applied Maths, Kortrijk, Belgium). PFGE clusters I to XXXI were assigned based on less than $90 \%$ similarity of banding patterns.

ESBL-positive E. coli strains, isolated mainly from urinary tract infections (56\%), exhibited resistance to ampicillin (100\%), cephalothin (100\%), ceftriaxone $(100 \%)$, cefotaxime $(100 \%)$, ceftazidime (79\%), cefepime (94\%), ciprofloxacin (50\%), sulfamethoxazole/trimethoprim (62\%), gentamicin $(56 \%)$ and amikacin $(6 \%)$, remaining susceptible to imipenem $(100 \%)$. All strains carried $b l a_{\text {СтХ-м-type }}$ genes, with $b l a_{\text {СтХ-M-2 }}$ being the most prevalent variant $(n=32)$, whereas the genes $b l a_{\text {СТХ-М-15 }}$ and $b l a_{\text {СТХ-М- } 1}$ were only found in one strain of E. coli (Table 1).
$X b a I$ PFGE analysis revealed the presence of 31 PFGE types among CTX-M producers (named clusters I to XXXI) (Figure 1), and phylogenetic investigation showed that low-virulence phylogenetic groups A $(18 \%)$ and $\mathrm{B} 1(52 \%)$ were predominant over highvirulence phylogenetic groups B2 (12\%) and D (18\%). Correlation between ESBL genotype and phylogenetic group revealed that of $18 \mathrm{E}$. coli isolates belonging to phylogenetic group B1, 16 isolates carried the bla $a_{\mathrm{CTX}}$ M-2 gene, whereas another two strains harbored the $b l a_{\text {CTX-М-1 }}$ and $b l a_{\text {СТХ-М-15 }}$ genes, respectively (Table 1 , Figure 1). The CTX-M-15-producing ExPEC belonged to the international sequence type ST648. In urinary tract infections, CTX-M-producing E. coli represented predominantly low-virulence phylogenetic group B1 $(57.9 \%)$. 
Table 1. Distribution of resistance profiles and CTX-M extended-spectrum $\beta$-lactamases types among Escherichia coli strains isolated from extra-intestinal infection according to phylogenetic group

\begin{tabular}{|c|c|c|c|c|c|c|c|c|c|c|c|c|c|c|c|}
\hline \multirow[b]{2}{*}{$\begin{array}{l}\text { Phylogenetic } \\
\text { group }\end{array}$} & \multicolumn{2}{|c|}{ Clinical samples (\%) } & \multicolumn{10}{|c|}{ Resistance profile $(\%)^{\mathrm{b}}$} & \multicolumn{3}{|c|}{ CTX-M ESBL gene (\%) } \\
\hline & urine & Others $^{\mathrm{a}}$ & AMP & KF & $\mathrm{CRO}$ & CTX & CAZ & FEP & CIP & SXT & GEN & $\mathrm{AK}$ & 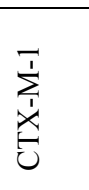 & 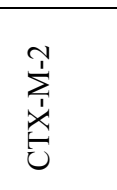 & 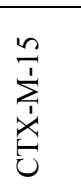 \\
\hline A & $3(9)$ & $3(9)$ & $6(18)$ & $6(18)$ & $6(18)$ & $6(18)$ & $5(15)$ & $6(18)$ & $4(12)$ & $3(9)$ & $2(6)$ & $1(3)$ & - & $6(18)$ & - \\
\hline B1 & $11(32)$ & $7(20)$ & $18(53)$ & $18(53)$ & $18(53)$ & $18(53)$ & $15(44)$ & $17(50)$ & $9(26)$ & $11(32)$ & $9(26)$ & - & $1(3)$ & $16(47)$ & $1(3)$ \\
\hline B2 & $1(3)$ & $3(9)$ & $4(12)$ & $4(12)$ & $4(12)$ & $4(12)$ & $3(9)$ & $4(12)$ & $1(3)$ & $2(6)$ & $4(12)$ & - & - & $4(12)$ & - \\
\hline D & $4(12)$ & $2(6)$ & $6(18)$ & $6(18)$ & $6(18)$ & $6(18)$ & $4(12)$ & $5(15)$ & $3(9)$ & $5(15)$ & $4(12)$ & $1(3)$ & - & $6(18)$ & - \\
\hline TOTAL & $19(56)$ & $15(44)$ & $34(100)$ & $34(100)$ & $34(100)$ & $34(100)$ & $27(79)$ & $32(94)$ & $17(50)$ & $21(62)$ & $19(56)$ & $2(6)$ & $1(3)$ & $32(94)$ & 1 (3) \\
\hline
\end{tabular}

ablood, tracheal fluid, bronchoalveolar, stump wound, cavity lavage, peritoneal fluid, biliar secretion, abscess, inguinal fold, axillary fold

'AMP, ampicillin; KF, cephalothin; CRO, ceftriaxone; CTX, cefotaxime; CAZ, ceftazidime; FEP, cefepime; CIP, ciprofloxacin; SXT, sulfamethoxazole/trimethoprim; GEN, gentamicin; AK, amikacin 
The results of the present study show that dissemination of $b l a_{\text {СTX-M }}$ genes (mainly $b l a_{\text {СТХ-М-2) }}$ is the leading cause of resistance to $\beta$-lactam antibiotics in $E$. coli strains isolated in the university hospital studied, whereas PFGE analysis revealed that the strains encompass a great genetic diversity, with the 34 strains presenting 31 different profiles (Figure 1), which is indicative of probable infection by $E$. coli strains of commensal origin. In fact, in this study, lowvirulence phylogenetic groups B1 and A were predominant over high-virulence phylogenetic groups B2 and D (Table 1). Phylogenetic analyses have shown that $E$. coli strains fall into four main phylogenetic groups (A, B1, B2, and D), and that virulent extra-intestinal strains belong mainly to group B2 and, to a lesser extent, to group D, whereas most commensal strains belong to A and B1 groups [1,2]. Therefore, most likely the widespread use of antibiotics in Brazil may be contributing to the selection of silent carriers of resistance genes among commensal strains. In fact, a study conducted in remote communities from the Brazilian Amazon region revealed that commensal $E$. coli from healthy children showed high levels of multidrug resistance [7]. Similar results were reported from Bolivian and Peruvian communities [8], where the identification of CTX-M ESBLs in E. coli from healthy children have been identified as a serious emerging threat [9]. CTX$M$ beta-lactamases had been widely distributed in South America at least since 1989, and possibly before appearing in Europe. After a period of CTX-M-2 prevalence, new CTX-M variants started to be progressively reported worldwide, with the international CTX-M-15-producing E. coli clone O25ST131 representing a major public health problem [10]. In Brazil, only a few MLST studies of ESBLproducing $E$. coli have been published $[11,12]$. In these studies, while predominance of ST410 (CC23) was observed among CTX-M-15-producing E. coli strains belonging to phylogroup A, MLST analysis indicated high genetic diversity among CTX-M-2producing E. coli strains in the Southeast region of Brazil $[11,12]$. In this study, we report further data on the identification of CTX-M-15-producing ExPEC belonging to the international sequence type ST648. ST648 with CTX-M-15 has previously been described in clinical isolates from USA [13], China [14], Netherlands [15], Canada [16], Korea [17] and Tanzania [18].

\section{Conclusion}

The spread of $b l a_{\text {СТХ-м }}$ genes is the main problem associated with resistance to cephalosporins in clinical isolates of $E$. coli at the university hospital studied. One finding of interest is the identification of CTX-M15-producing $E$. coli belonging to the international sequence type ST648, which had not previously been reported in this region. The predominance of lowvirulence phylogenetic groups A and B1 among CTXM-producing ExPEC strains suggests that, in this study, most EI infections caused by ESBL-producing $E$. coli are endogenous, probably resulting from infection with strains of commensal origin that can play key roles as reservoirs of antibiotic resistance genes and as drug-resistant pathogens, which is a worrisome prospect, given that $E$. coli is ubiquitous among humans and other animals that can serve as hosts.

\section{Acknowledgements}

FAPESP and CNPq are gratefully acknowledged for the financial support of this research. N.L. is a research fellow of CNPq. We thank Cefar Diagnóstica Ltda. (São Paulo, Brazil) for kindly supplying antibiotic discs for susceptibility testing, and Dr. Marina Baquerizo Martinez (Director of the Clinical Laboratory of the University Hospital, University of São Paulo) for kindly providing strains to this study.

\section{References}

1. Johnson JR and Russo R (2002) Extraintestinal pathogenic Escherichia coli: "The other bad E. coli". J Lab Clin Med 139: 155-162.

2. Clermont O, Bonacorsi S, Bingen E (2000) Rapid and simple determination of the Escherichia coli phylogenetic group. Appl Environ Microbiol 66: 4555-4558.

3. Feldgarden M (2010) Resistance in reservoirs and human commensals. In Sosa AJ, Byarugaba DK, Amábile-Cuevas CF, Hsueh P-R, Kariuki S, Okeke IN, editors. Antimicrobial Resistance in Developing Countries. Springer Science+Business Media, New York, pp. 267-79.

4. Rodríguez-Baño J and Pascual A (2008) Clinical significance of extended-spectrum beta-lactamases. Expert Rev Anti Infect Ther 6: 671-683.

5. Clinical and Laboratory Standards Institute (2011) Performance Standards for Antimicrobial Susceptibility Testing. Twenty-first informational supplement. Document M100-S21. CLSI: Wayne, PA.

6. Tollentino FM, Polotto M, Nogueira ML, Lincopan N, Neves P, Mamizuka EM, Remeli GA, De Almeida MT, Rúbio FG, Nogueira MC (2011) High prevalence of bla(CTX-M) extended spectrum beta-lactamase genes in Klebsiella pneumoniae isolates from a tertiary care hospital: first report of bla(SHV-12), bla(SHV-31), bla(SHV-38), and bla(CTXM-15) in Brazil. Microb Drug Resist 17: 7-16. 
7. Nascimento AMA, Campos CEP, Campos EP, Azevedo JL, Chartone-Souza E (1999) Re-evaluation of antibiotic and mercury resistance in Escherichia coli populations isolated in 1978 from Amazonia rubber tree tappers and Indians. Res Microbiol 150: 407-411.

8. Bartoloni A, Pallecchi L, Bendetti M, Fernandez C, Vallejos Y, Guzman E, Villagra AL, Mantella A, Lucchetti C, Bartalesi F, Strohmeyer M, Bechini A, Gamboa H, Rodriguez H, Falkenberg T, Kronvall G, Gotuzzo E, Paradisi F, Rossolini GM (2006) Multidrug-resistant commensal Escherichi coli in children, Peru and Bolivia. Emerg Infect Dis 12: 907-913.

9. Pallecchi L, Bartoloni A, Fiorelli C, Mantella A, Di Maggio T, Gamboa H, Gotuzzo E, Kronvall G, Paradisi F, Rossolini GM (2007) Rapid dissemination and diversity of CTX-M extended-spectrum beta-lactamase genes in commensal Escherichia coli isolates from healthy children from lowresource settings in Latin America. Antimicrob Agents Chemother 51: 2720-2725.

10. Peirano G and Pitout JD (2010) Molecular epidemiology of Escherichia coli producing CTX-M beta-lactamases: the worldwide emergence of clone ST131 O25:H4. Int J Antimicrob Agents 35:316-321.

11. Peirano G, Asensi MD, Pitondo-Silva A, Pitout JD (2011) Molecular characteristics of extended-spectrum $\beta$-lactamaseproducing Escherichia coli from Rio de Janeiro, Brazil. Clin Microbiol Infect 17: 1039-1043.

12. Minarini LA, Gales AC, Palazzo IC, Darini AL (2007) Multilocus sequence typing of uropathogenic ESBLproducing Escherichia coli isolated in a Brazilian community. Curr Microbiol 55: 524-529.

13. Sidjabat HE, Paterson DL, Adams-Haduch JM, Ewan L, Pasculle AW, Muto CA, Tian GB, Doi Y (2009) Molecular epidemiology of CTX-M-producing Escherichia coli isolates at a tertiary medical center in western Pennsylvania. Antimicrob Agents Chemother 53: 4733-4739.

14. Zong Z and Yu R (2010) Escherichia coli carrying the bla $a_{\mathrm{CTX}-}$ M-15 gene of ST648. J Med Microbiol 59: 1536-1537.

15. Van der Bij AK, Peirano G, Goessens WH, van der Vorm ER, van Westreenen M, Pitout JD (2011) Clinical and molecular characteristics of extended-spectrum-beta-lactamaseproducing Escherichia coli causing bacteremia in the Rotterdam Area, Netherlands. Antimicrob Agents Chemother 55: 3576-3578.

16. Van der Bij AK, Peirano G, Pitondo-Silva A, Pitout JD (2012) The presence of genes encoding for different virulence factors in clonally related Escherichia coli that produce CTXMs. Diagn Microbiol Infect Dis 72: 297-302.

17. Park SH, Byun JH, Choi SM, Lee DG, Kim SH, Kwon JC, Park C, Choi JH, Yoo JH (2012) Molecular epidemiology of extended-spectrum $\beta$-lactamase-producing Escherichia coli in the community and hospital in Korea: emergence of ST131 producing CTX-M-15. BMC Infect Dis 12: 149.

18. Mshana SE, Imirzalioglu C, Hain T, Domann E, Lyamuya EF, Chakraborty T (2011) Multiple ST clonal complexes, with a predominance of ST131, of Escherichia coli harbouring $b l a_{\text {CTX-M-15 }}$ in a tertiary hospital in Tanzania. Clin Microbiol Infect 17: 1279-1282.

\section{Corresponding author}

Professor Nilton Lincopan, PhD

Department of Microbiology

Institute of Biomedical Sciences

Universidade de São Paulo, Brazil

Email: lincopan@usp.br

Telephone: +55-11-30917296

Conflict of interests: No conflict of interests is declared. 